\title{
Photoexcitation of Grubbs' Second-Generation Catalyst Initiates Frontal Ring-Opening Metathesis Polymerization
}

Katherine J. Stawiasz, $\uparrow, \perp$ Justine E. Paul $, \sharp, \perp$ Kevin J. Schwarz, $\uparrow$ Nancy R. Sottos, $₫, \perp$ Jeffrey S. Moore*,†,

†Department of Chemistry, University of Illinois at Urbana-Champaign, Urbana, Illinois 61801, United States ¥ Department of Materials Science and Engineering, University of Illinois at Urbana-Champaign, Urbana, Illinois 61801, United States

${ }_{\perp}$ Beckman Institute for Advanced Science and Technology, University of Illinois at Urbana-Champaign, Urbana, Illinois 61801, United States

* Corresponding author. E-mail: jsmoore@illinois.edu

Table of Contents:

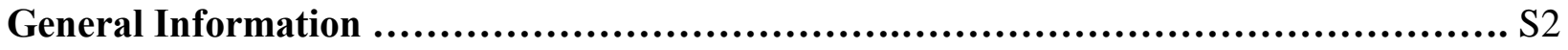

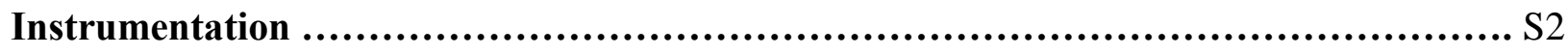

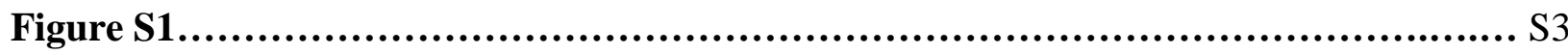

Materials for FROMP............................................................... S3

General Procedure 1 for Thermally Activated FROMP .................................. S3

General Procedure 2 for UV-Activated FROMP ..................................... S4

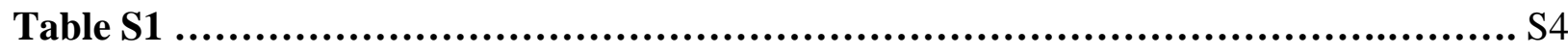

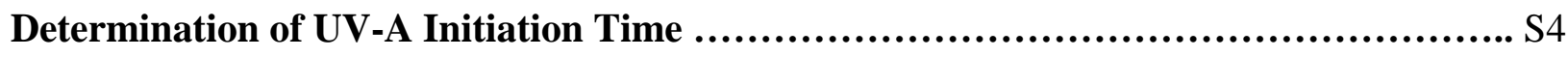

Figure $\mathbf{S 2}$......................................................................... S5

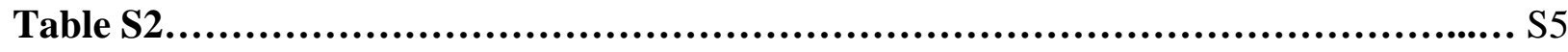

DSC Experiments................................................................... S5

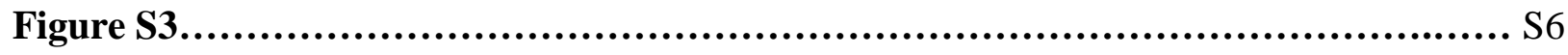

Table S3........................................................................... S6

Table S4..................................................................................... S6

Penetration Depth.................................................................... S7

Figure $\mathbf{S 4}$....................................................................... S7

UV-Vis Spectra (Figure S5) ...................................................... S7-S8

Figure $\mathrm{S6}$.......................................................................... S9

General Procedure 3 for RCM (Scheme S1) ........................................... S9

Synthetic Procedures............................................................... S10-S11

NMR Characterization ....................................................... S $12-\mathrm{S} 17$ 


\section{General Information}

Unless otherwise noted, all reactions have been carried out with distilled and degassed solvents under an atmosphere of dry $\mathrm{N}_{2}$ in flame or oven dried glassware with standard vacuum-line techniques. All reactions were carried out in glass round-bottom flasks with rubber septa and magnetic stirring unless otherwise indicated. Dichloromethane and acetonitrile were purified under a positive pressure of dry argon by passage through two columns of activated alumina. Toluene was purified under a positive pressure of dry argon by passage through columns of activated alumina and Q5 (Grubbs apparatus). Benzene was dried and purified following the guidelines of Perrin and Armarego. ${ }^{1}$ All workup and purification procedures were carried out with reagent grade solvents (purchased from Sigma-Aldrich) in air. Standard column chromatography techniques using ZEOprep 60/40-63 $\mu \mathrm{m}$ silica gel were used for purification. Liquids and solutions were transferred via syringe.

\section{Instrumentation:}

NMR: ${ }^{1} \mathrm{H}$ and ${ }^{13} \mathrm{C}$ NMR spectra were recorded at room temperature on Varian Inova-instrumentation Varian VXR500 $\left({ }^{1} \mathrm{H}\right.$ NMR at $500 \mathrm{MHz}$ and ${ }^{13} \mathrm{C}$ NMR at $\left.126 \mathrm{MHz}\right)$ or Brulker CB500 with cryoprobe $\left({ }^{1} \mathrm{H} \mathrm{NMR}\right.$ at $500 \mathrm{MHz}$ and ${ }^{13} \mathrm{C}$ NMR at $126 \mathrm{MHz}$ ), using deuterium lock. Data for ${ }^{1} \mathrm{H}$ NMR spectra are quoted relative to chloroform or toluene as an internal standard (7.26 ppm or $2.09 \mathrm{ppm})$ and data for ${ }^{13} \mathrm{C}$ NMR spectra are quoted relative to chloroform or toluene as an internal standard $(77.23 \mathrm{ppm}$ or $128.39 \mathrm{ppm})$ and are reported in terms of chemical shift $(\delta \mathrm{ppm})$. Data are reported as follows: chemical shift, integration, multiplicity $(\mathrm{s}=$ singlet, $\mathrm{d}=$ doublet, $\mathrm{t}=$ triplet, $\mathrm{q}$ $=$ quartet, $\mathrm{br}=$ broad, $\mathrm{m}=$ multiplet $)$, and coupling constants $(\mathrm{Hz})$.

Mass Spec: High Resolution Mass (HRMS) analysis was obtained using Electrospray Ionization (ESI) and reported as $\mathrm{m} / \mathrm{z}$ (relative intensity) for the $[\mathrm{M}+\mathrm{H}]^{+}$or $[\mathrm{M}+\mathrm{Na}]^{+}$molecular ion.

UV-Vis: UV-Vis absorption spectra were recorded in HPLC Grade dichloromethane (DCM) on a Shimadzu UV2401 PC UV-Vis Spectrophotometer at a concentration of $77 \mu \mathrm{M}$.

Differential Scanning Calorimetry (DSC): Differential scanning calorimetry (DSC) liquid resin cure kinetic measurements were performed with a TA Instruments Q250 differential scanning calorimeter. Samples were transferred into aluminum hermetic DSC pans at room temperature and sealed. The sample mass is determined using an analytical balance (XPE205, Mettler-Toledo) and was carefully maintained between $2 \mathrm{mg}$ and $3 \mathrm{mg}$. The specific heat capacity is determined between $25^{\circ} \mathrm{C}$ and $200^{\circ} \mathrm{C}$ by comparison with a sapphire standard.

Light Sources and Set-up: A Novacure N2001 ultraviolet/visible spot cure system (Artisan Technology Group) with a mercury vapor lamp and a fiber optic guide was used as a white light source with an emission spectrum of $250-800 \mathrm{~nm}$ and a maximum output intensity of $27 \mathrm{~W}$. Two filters were used that allowed enhancements of the output refinements for specific conditions. A single wavelength bandpass filter of $365 \mathrm{~nm}(4.7 \mathrm{~W})$ was used as well as a bandpass filter $320-500 \mathrm{~nm}(17 \mathrm{~W})$.

A ThorLabs $375 \mathrm{~nm}$ mounted LED diode attached to a SM1 lens tube with two lenses for collimation; an aspheric condenser lens (Ø1", $\mathrm{f}=16 \mathrm{~mm}, \mathrm{NA}=0.79$, ARC: 350-700 nm) and bi-convex lens( $\varnothing 1 ", \mathrm{f}=150.0 \mathrm{~mm}$, ARC: 350$700 \mathrm{~nm}$ ). A T-Cube LED driver set to the continuous mode was used to control the LED intensity, allowing for a maximum irradiance of $318 \mathrm{~mW} / \mathrm{cm}^{2}$. The irradiance of the UV light was calculated by dividing the light power output by the illumination area on the focal plane $\left(1.305 \mathrm{~cm}^{2}\right)$ in order to get its irradiance in $\mathrm{mW} / \mathrm{cm}^{2}$. Respectively, the UV-A maximum power output $(415 \mathrm{~mW})$ was measured using a power meter. A $455 \mathrm{~nm}$ LED diode was also purchased, and easily replaced the $375 \mathrm{~nm}$ LED diode on the existing set-up.

\footnotetext{
${ }^{1}$ D. D. Perrin, W. L. F. Amarego, Purification of Laboratory Chemicals, Pergamon, Press, @ Oxford, ed. $3,1988$.
} 


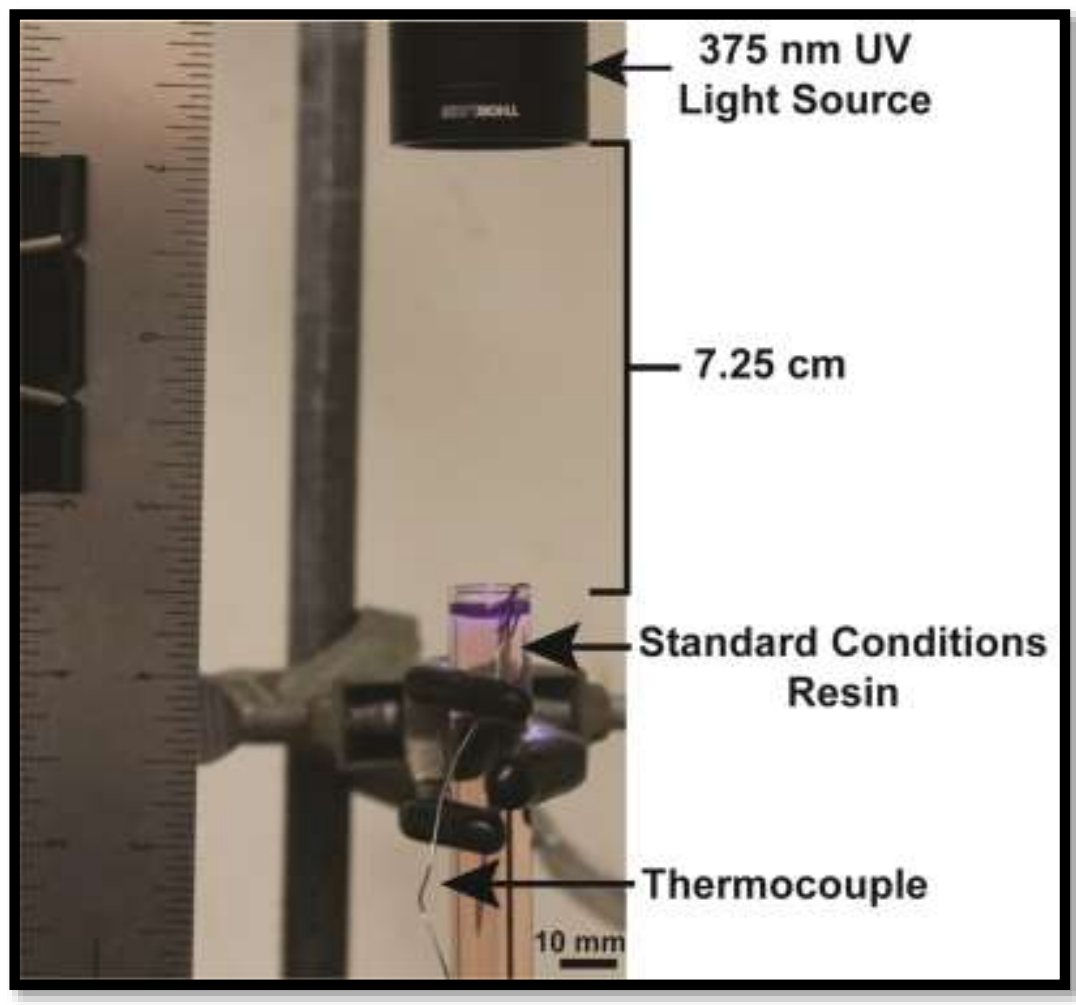

Figure S1. Experimental set-up for UV-activated FROMP.

\section{Materials for Frontal Ring-Opening Metathesis Polymerization}

Dicyclopentadiene (DCPD), 5-ethylidene-2-norbornene (ENB), Grubbs' second-generation catalyst (GC2) and tributylphosphite $\left(\mathrm{P}\left(\mathrm{O}^{n} \mathrm{Bu}\right)_{3}\right)$, were purchased from Millipore Sigma and used as received without further purification. Since DCPD is a solid at room temperature, $5 \mathrm{wt} \%$ ENB was added to depress the melting point. All references to DCPD herein refer to this 95:5 DCPD:ENB solution.

\section{General Procedure 1 for Thermally Activated Frontal Ring-Opening Metathesis Polymerization}

To a $20 \mathrm{~mL}$ scintillation vial was added $6.42 \mathrm{mg}$ of GC2 ( $0.0076 \mathrm{mmol}, 1$ equiv.). $10 \mathrm{~g}$ of DCPD (76 mmol, 10,000 equiv.) was added to a $20 \mathrm{~mL}$ scintillation vial followed by addition of $2 \mu \mathrm{L}$ of $\mathrm{P}\left(\mathrm{O}^{n} \mathrm{Bu}\right)_{3}(0.0076 \mathrm{mmol})$ by microliter syringe. This solution was shaken and added to the vial containing GC2. The solution was sonicated for 5 minutes prior to pouring into a $13 \times 100 \mathrm{~mm}$ test tube. A soldering iron was then applied to the test tube near the surface of the liquid, and FROMP proceeded in a descending mode. Once frontal polymerization was initiated, the soldering iron was removed, and the propagation was monitored using a Canon Rebel T4i DSLR. Frontal velocities were measured using Tracker®, an open source physics (OSP) video analysis and modeling tool. Using the built-in tracking feature, position, time, and velocity were extracted from the videos. Each video was analyzed three times and the front velocity of the sample was determined by the average of the three analyses. 


\section{General Procedure 2 for UV-Activated Frontal Ring-Opening Metathesis Polymerization}

To a $20 \mathrm{~mL}$ scintillation vial was added $6.42 \mathrm{mg}$ of GC2 ( $0.0076 \mathrm{mmol}, 1$ equiv.). $10 \mathrm{~g}$ of DCPD (76 mmol, 10,000 equiv.) was added to a $20 \mathrm{~mL}$ scintillation vial followed by addition of $2 \mu \mathrm{L}$ of $\mathrm{P}\left(\mathrm{O}^{\mathrm{n}} \mathrm{Bu}\right)_{3}(0.0076 \mathrm{mmol})$. This solution was shaken and added to the vial containing GC2. The solution was sonicated for 5 minutes prior to pouring into a $13 \times 100 \mathrm{~mm}$ test tube equipped with a thermocouple in the top of the solution. A $375 \mathrm{~nm}$ LED (318 $\mathrm{mW} / \mathrm{cm}^{3}$ ) was positioned approximately $7.5 \mathrm{~cm}$ above the surface of the liquid and turned on (Figure S1). Once frontal polymerization was initiated, the LED was turned off and the propagation was monitored using a Canon Rebel T4i DSLR. Frontal velocities were measured using Tracker®, an open source physics (OSP) video analysis and modeling tool. Using the built-in tracking feature, position, time, and velocity were extracted from the videos. Each video was analyzed a total of three times and the front velocity of the sample was determined by the average of the three analyses.

Table S1. Front Speed measurements of various GC2 loadings for both UV-A light and thermally activated samples $(\mathrm{n}=3)$.

\begin{tabular}{ccc} 
& $\begin{array}{c}\text { Front Speed } \\
(\mathbf{m m} / \mathbf{s e c})\end{array}$ & \\
\hline $\begin{array}{c}\text { GC2 Loading } \\
(\mathbf{p p m})\end{array}$ & $\begin{array}{c}\text { UV-A Light } \\
\text { Activated }\end{array}$ & $\begin{array}{c}\text { Thermal } \\
\text { Activated }\end{array}$ \\
\hline 50 & $0.89 \pm 0.04$ & $0.75 \pm 0.10$ \\
100 & $1.25 \pm 0.11$ & $1.28 \pm 0.08$ \\
200 & $1.69 \pm 0.03$ & $1.82 \pm 0.32$ \\
300 & $1.75 \pm 0.08$ & $1.95 \pm 0.19$
\end{tabular}

\section{Determination of UV-A Initiation Times}

A T-type thermocouple (SCPSS, Omega Engineering) was attached firmly at the top surface of the 95:5 DCPD:ENB resin in a glass test tube $(13 \times 100 \mathrm{~mm})$. The junction of the thermocouple was positioned level with the light source. The test tube was then filled with $10 \mathrm{~mL}$ of sonicated DCPD resin. The light source was turned on until initiation of frontal polymerization occurred. The thermocouple monitored the temperature continuously. Representative temperature profiles are shown in Figure 2 in the main text for the $375 \mathrm{~nm}$ LED Diode light from ThorLabs. Different light sources were also used with varying light intensity $\left(\mathrm{mW} / \mathrm{cm}^{2}\right)$ and wavelength $(\mathrm{nm})$ and the initiation times along with temperature profiles can also be observed in the main text.

The thermocouple was also used to determine the time to activation for various GC2 loadings for the $375 \mathrm{~nm}$ LED diode $\left(318 \mathrm{~mW} / \mathrm{cm}^{2}\right)$ light source. When frontal polymerization occurred due to photoexcitation of the ruthenium catalyst, there was a dramatic increase in temperature $\left(\mathrm{T}>150^{\circ} \mathrm{C}\right)$ as the exothermic polymerization front passed by the thermocouple junction. The time to activation was determined as the time in which this massive temperature spike occurred. The fastest initiation event was for $50 \mathrm{ppm}$ loadings of GC2 and the time to initiation increased rather linearly as the loadings increased while a more dramatic time increase can be seen for lower loadings. There is however a limit to the amount of GC2 that can be added. At loadings of $12.5 \mathrm{ppm}$ FROMP does not occur after 1 hour, but the entire sample's viscosity increases, and the sample becomes gel-like. At loadings of $350 \mathrm{ppm}$ and higher, FROMP also does not transpire after an hour. The top layer of the resin that was exposed to UV-A light also becomes gel like with the rest of the sample remaining a liquid. 


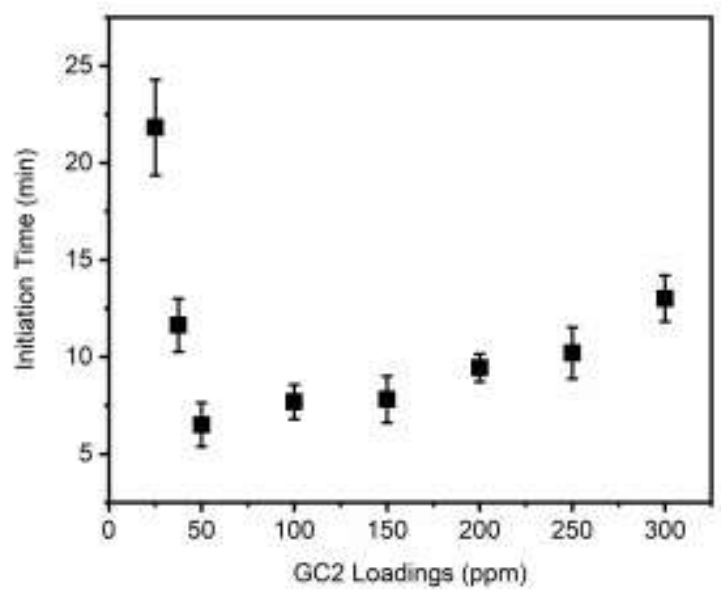

Figure S2. Summary of the time to photo-initiate under irradiation of $318 \mathrm{~mW} / \mathrm{cm}^{2}(375 \mathrm{~nm})$ for resins with different GC2 loadings ( $\mathrm{n}=3$ for all data points). The time to initiate increases above and below $50 \mathrm{ppm}$ loading. It should be noted that $12.5 \mathrm{ppm}$ does not gel/FROMP for thermally initiated samples. With light, the sample gels after 1 hour but no FROMP is observed. The lower limit found for photo-initiation is 25 minutes, as shown on the Figure above.

Table S2. Initiation times of each GC2 loading as shown in Figure S2.

\begin{tabular}{cc} 
GC2 Loading (ppm) & Initiation Time (min) \\
\hline 25 & $21.8 \pm 2.5$ \\
37.5 & $11.6 \pm 1.4$ \\
50 & $6.5 \pm 1.1$ \\
100 & $7.7 \pm 0.9$ \\
150 & $7.8 \pm 1.2$ \\
200 & $9.4 \pm 0.7$ \\
250 & $10.2 \pm 1.3$ \\
300 & $13.0 \pm 1.2$
\end{tabular}

\section{Differential Scanning Calorimetry Experiments}

Samples of DCPD:ENB resin $(2-3 \mathrm{mg})$ were subjected to thermal scans from $-50{ }^{\circ} \mathrm{C}$ to $250{ }^{\circ} \mathrm{C}$ at a constant ramp rate to determine the cure kinetics. The heat released during the polymerization was calculated by integrating the exotherm peak ca. $390 \mathrm{~J} / \mathrm{g}$. In order to ensure that there was no thermal effects driving the start of polymerization and that it was purely a photoexcitation of GC2 event, we performed isothermal holds were performed on the DCPD:ENB resin (2-3 mg) over the course of 20 minutes. The heat released during each isothermal hold was calculated by integrating the exotherm peak. The degree of cure was calculated for each sample by dividing the heat released during the isothermal event by the total heat released for a sample during a dynamic scan $(390 \mathrm{~J} / \mathrm{g})$. 


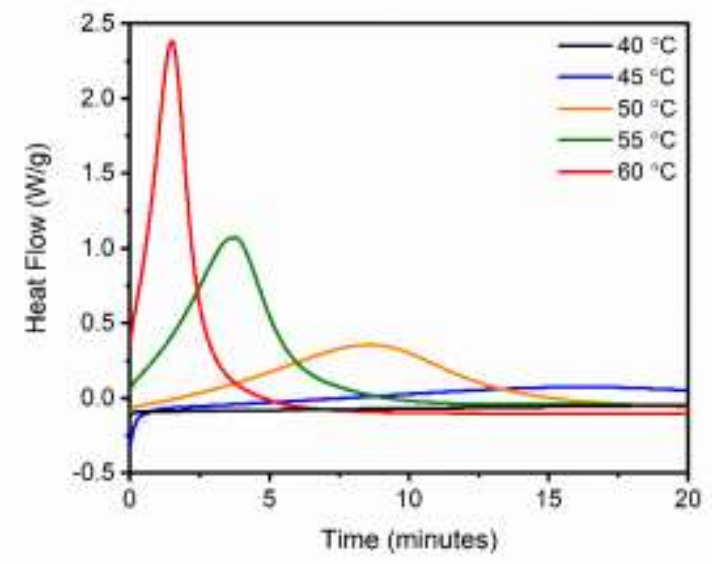

Figure S3. Representative DSC curves for DCPD:ENB resin during the isothermal scans at various temperatures.

Table S3. Degree of cure for each sample held isothermally

\begin{tabular}{ccc}
\hline $\begin{array}{c}\text { Isothermal } \\
\text { Temperature }\left({ }^{\circ} \mathbf{C}\right)\end{array}$ & $\begin{array}{c}\text { Heat of Enthalpy } \\
(\mathbf{J} / \mathbf{g})\end{array}$ & $\begin{array}{c}\text { Degree of Cure } \\
(\boldsymbol{\%})\end{array}$ \\
\hline 40 & 2.4 & 0.62 \\
45 & 50 & 12.8 \\
50 & 185 & 47.4 \\
55 & 198 & 50.8 \\
60 & 235 & 60.3
\end{tabular}

Samples of frontally polymerized pDCPD (5-10 mg) were subjected to ramp scans from $-50{ }^{\circ} \mathrm{C}$ to $250{ }^{\circ} \mathrm{C}$ at $10{ }^{\circ} \mathrm{C} / \mathrm{min}$. The glass transition, $T_{\mathrm{g}}$ was determined by taking the midpoint of the thermal transition during the second heating. As a result, all $T_{\mathrm{g}}$ 's listed are approximate (Table S3). Samples activated thermally and by UV-A light exhibited $T_{\mathrm{g}}$ values between $160-170{ }^{\circ} \mathrm{C}$. No significant differences based on stimulus type were observed.

Table S4. Summary of glass transition temperatures for each loading of GC2 for both thermally and photo activated $\mathrm{pDCPD}(\mathrm{n}=3)$.

\begin{tabular}{ccc} 
& $\boldsymbol{T}_{\mathbf{g}}\left({ }^{\circ} \mathbf{C}\right)$ & $\boldsymbol{T}_{\mathbf{g}}\left({ }^{\circ} \mathbf{C}\right)$ \\
\hline $\begin{array}{c}\text { GC2 Loading } \\
(\mathbf{p p m})\end{array}$ & $\begin{array}{c}\text { UV-A Light } \\
\text { Activated }\end{array}$ & $\begin{array}{c}\text { Thermal } \\
\text { Activated }\end{array}$ \\
\hline 50 & $164 \pm 0.6$ & $164 \pm 1.0$ \\
100 & $167 \pm 0.6$ & $167 \pm 1.5$ \\
200 & $167 \pm 0.6$ & $168 \pm 1.7$ \\
300 & $168 \pm 1.0$ & $168 \pm 1.5$
\end{tabular}




\section{Penetration Depths via Infrared Analysis}

Samples of tetrahydro-DCPD dissolved in a minimal amount of toluene was used in place of 95:5 DCPD:ENB. This solution also contained $100 \mathrm{ppm}$ of $\mathbf{G C 2}$ and $\mathrm{P}\left(\mathrm{O}^{\mathrm{n}} \mathrm{Bu}\right)_{3}$ to accurately reflect the standard conditions without worry about polymerization occurring. $3.5 \mathrm{~mL}$ of this solution was pipetted into a quartz cuvette purchased from Cole Palmer. The $375 \mathrm{~nm}$ UV-A light was setup to accurately reflect the experimental setup shown above. The maximum irradiance $\left(318 \mathrm{~mW} / \mathrm{cm}^{2}\right)$ was used for all samples and an Infrared (IR) camera was used to capture the temperature profile during irradiation. As observed below in Figure S4, the penetration depth decreased as loading of GC2 increased. As a result, this decreased penetration depth can help support why the initiation time per GC2 loading increased with an increase in loading.

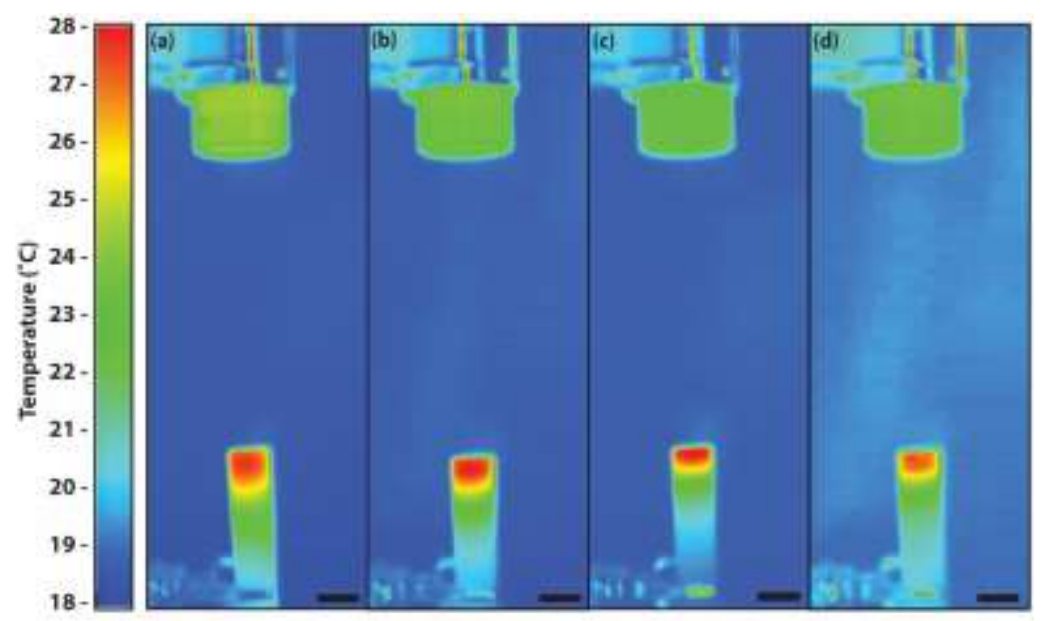

Figure S4. IR camera images showing representative penetration depths for various GC2 loadings; (a) 50ppm, (b) 100ppm, (c) 200ppm, (d) 300ppm. Scale bars in each image represent $1 \mathrm{~cm}$.

\section{UV-Vis Spectra}

(a)

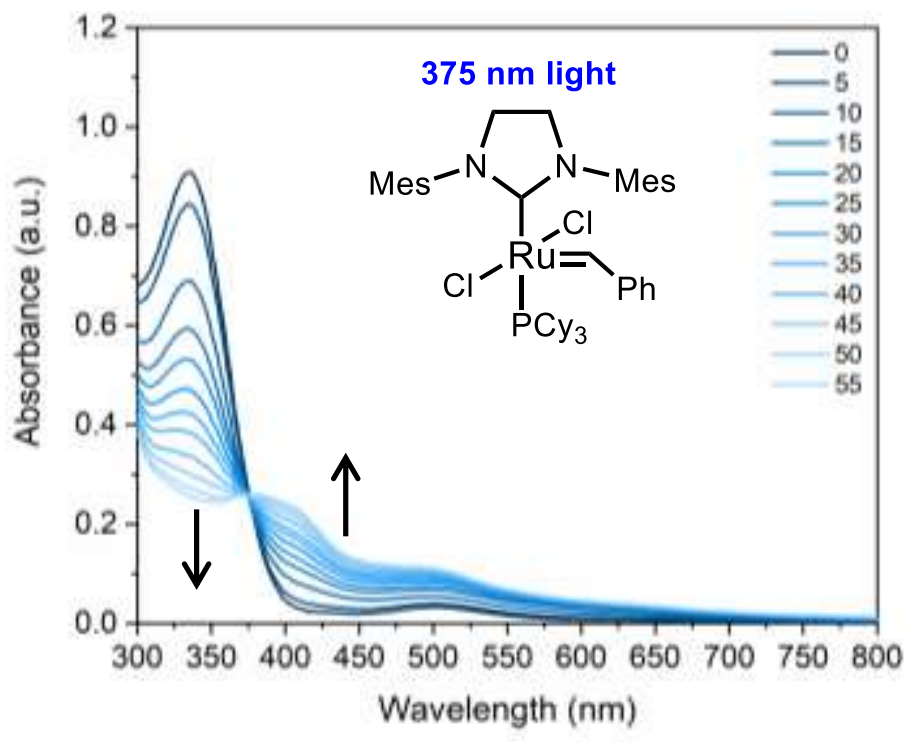


(b)

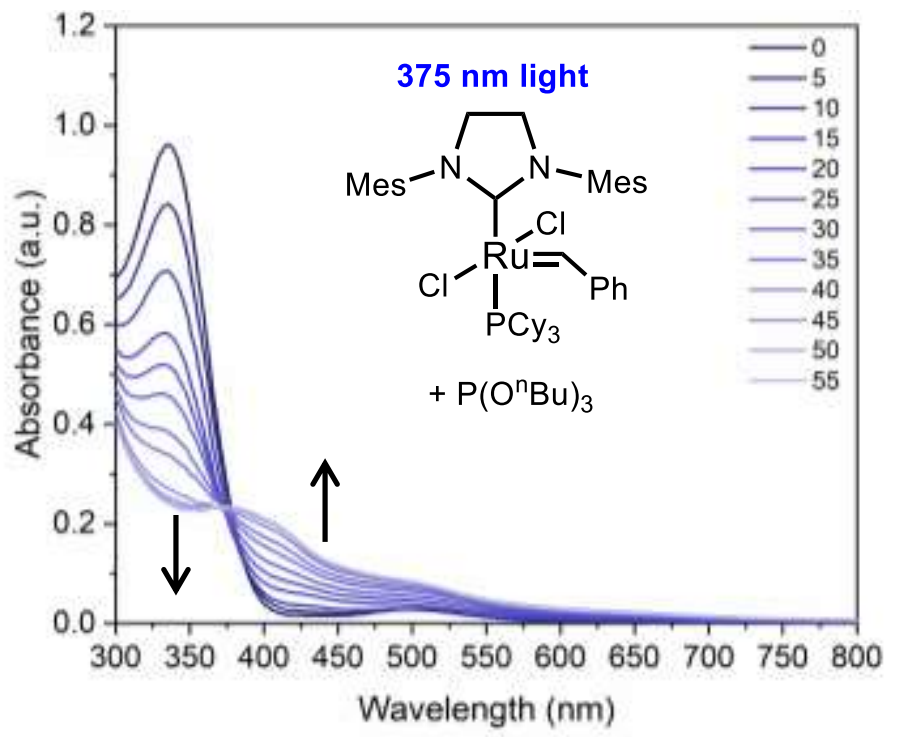

(c)

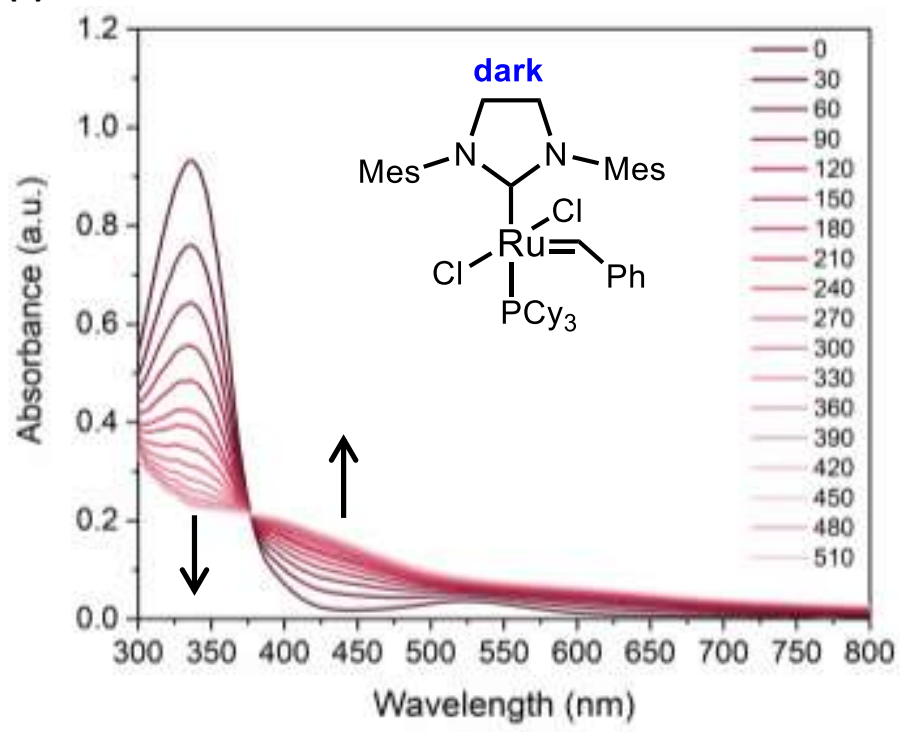

Figure S5. UV-Vis of GC2 samples at $77 \mu \mathrm{M}$ in DCM. (a) GC2 exposed to $375 \mathrm{~nm}$ light, with spectra collected every 5 minutes. (b) $\mathbf{G C 2}$ and $\mathrm{P}\left(\mathrm{O}^{\mathrm{n}} \mathrm{Bu}\right)_{3}$ exposed to $375 \mathrm{~nm}$ light, with spectra collected every 5 minutes. (c) GC2 in UV-Vis spectrometer, with spectra collected every 10 minutes (every 30 minutes shown for clarity). In all cases, the legend corresponds to a value of time in minutes.

For Grubbs' Second-Generation catalyst, $\lambda_{\max }=342 \mathrm{~nm}$ and is reported to be the metal to ligand charge transfer (MLCT) band. ${ }^{2}$ This band decreases in intensity while wavelengths in the visible region grow in intensity. The catalyst solution makes an irreversible color change from red to yellow.

2 Sanford, M. S.; Love, J. A.; Grubbs, R. H. Mechanism and Activity of Ruthenium Olefin Metathesis Catalysts. J. Am. Chem. Soc. 2001, 123 (27), 6543-6554. https://doi.org/10.1021/ja010624k. 

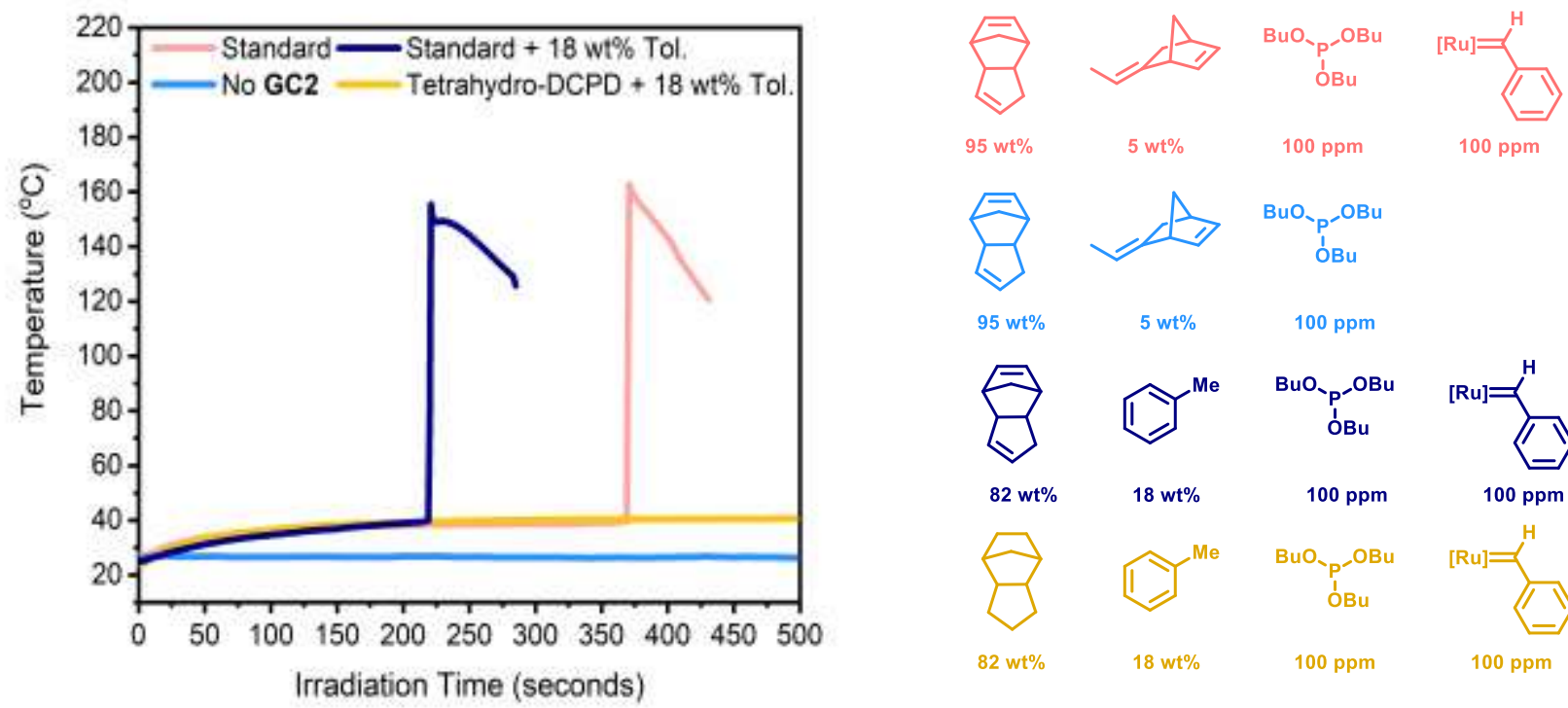

100 ppm

100 ppm

BuO.

$\mathrm{OBu}$

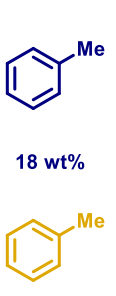

100 ppm

BuO.

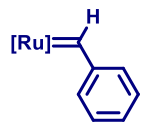

100 ppm

100 ppm

$\mathrm{BuO}_{\mathrm{P}^{-}}-\mathrm{OBu}^{\prime}$
ÓBu

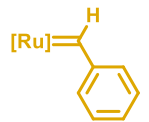

$82 \mathrm{wt} \%$

$18 w t \%$

100 ppm

100 ppm

Figure S6. Solution temperature over time, measured by a thermocouple. Standard conditions (pink): $10 \mathrm{~mL}$ monomer solution, 100 ppm GC2, 100 ppm $\mathrm{P}\left(\mathrm{O}^{\mathrm{n}} \mathrm{Bu}\right)_{3}$. No GC2 conditions (light blue): same as standard, without catalyst. Standard in toluene (purple): $10 \mathrm{~mL}$ solution of 82:18 DCPD: toluene, $100 \mathrm{ppm}$ GC2, $100 \mathrm{ppm} \mathrm{P}\left(\mathrm{O}^{\mathrm{n}} \mathrm{Bu}\right)_{3}$.Tetrahydro-DCPD conditions (yellow): $10 \mathrm{~g}$ of monomer (no ENB), $100 \mathrm{ppm} \mathrm{GC2,} 100 \mathrm{ppm} \mathrm{P}\left(\mathrm{O}^{\mathrm{n}} \mathrm{Bu}\right)_{3}$. ENB was omitted in the purple and yellow curves to prevent frontal polymerization.

\section{General Procedure 3 for Ring-Closing Metatheses}
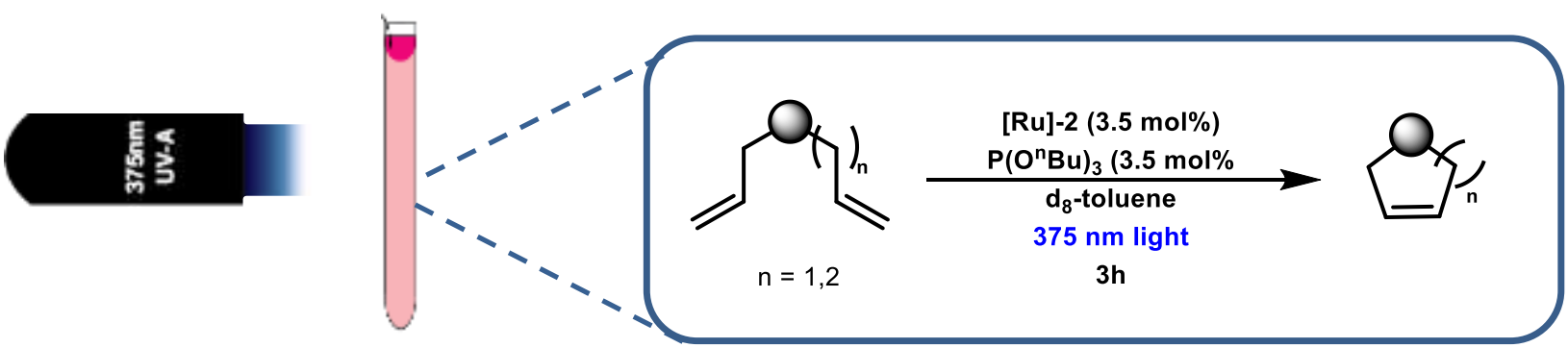

Scheme S1. Set-up for UV accelerated RCM studies.

To an oven dried NMR tube*, the corresponding amount of diene $(0.1 \mathrm{mmol})$ was added, followed by a $0.7 \mathrm{mM}$ solution in toluene- $d_{8}(0.5 \mathrm{~mL})$ of Grubbs' Second-Generation catalyst $(2.9 \mathrm{mg}, 0.35 \mu \mathrm{mol}, 3.5 \mathrm{~mol} \%)$ and tributyl phosphite $(0.95 \mu \mathrm{L}, 3.5 \mathrm{~mol} \%)$. Reactions were kept at room temperature for 3 hours, either in the presence of light (as shown in Scheme 1, above) or wrapped in aluminum foil, before NMR data were collected. Solvent was removed via rotary evaporation before dissolving in DCM and filtering through a plug of silica to remove the remaining catalyst. Column chromatography on silica gel $(0 \rightarrow 10 \%$ gradient ethyl acetate in hexanes) was used to separate desired products from unreacted starting material in cases where the reaction did not go to completion.

*5 mm Thin Wall Precision Quartz NMR Sample Tubes (7" length, 500MHz) purchased from Wilmad-LabGlass were used for the UV-irradiation experiments. 


\section{Synthetic Procedures}

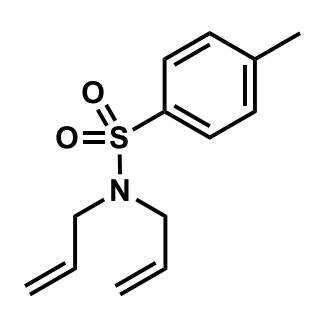

N,N-diallyl-4-methylbenzenesulfonamide. Triethylamine $(2.9 \mathrm{~mL}, 21 \mathrm{mmol})$ and 4 dimethylaminopyridine $(256 \mathrm{mg}, 2.1 \mathrm{mmol})$ were added to a solution of diallylamine (1.3 $\mathrm{mL}, 10.5 \mathrm{mmol}$ ) in $35 \mathrm{~mL}$ of dichloromethane. The solution was cooled to $0{ }^{\circ} \mathrm{C}$ before slowly adding tosyl chloride $(2.2 \mathrm{~g}, 11.6 \mathrm{mmol})$. The reaction was brought to room temperature and stirred overnight. Reaction mixture was monitored using 90:10 dichloromethane: methanol. The organic phase was washed first over $1 \mathrm{M} \mathrm{HCl}$, then water, then $1 \mathrm{M} \mathrm{NaOH}$, dried over $\mathrm{MgSO}_{4}$, and concentrated under rotary evaporation to yield 2.52 g (95\%) of the title compound as a colorless oil. ${ }^{1} \mathbf{H}$ NMR $\left(500 \mathrm{MHz}\right.$, Toluene- $\left.d_{8}\right) \delta 7.61(\mathrm{~d}, J=8.3 \mathrm{~Hz}, 2 \mathrm{H}), 6.79$ $(\mathrm{d}, J=8.0 \mathrm{~Hz}, 2 \mathrm{H}), 5.49(\mathrm{ddt}, J=16.6,10.1,6.3 \mathrm{~Hz}, 2 \mathrm{H}), 4.92-4.85(\mathrm{~m}, 4 \mathrm{H}), 3.66(\mathrm{~d}, J=6.3 \mathrm{~Hz}, 4 \mathrm{H}), 1.95(\mathrm{~s}$, 3H). ${ }^{13}$ C NMR (125 MHz, Chloroform- $d$ ) $\delta$ 143.32, 137.52, 132.77, 129.78, 127.27, 119.06, 49.44, 21.62. HRMS (ESI): $\mathrm{m} / z$ calcd for $[\mathrm{M}+\mathrm{H}]^{+} \mathrm{C}_{13} \mathrm{H}_{18} \mathrm{NO}_{2} \mathrm{~S}: 252.1058$ Found: 252.1058 .

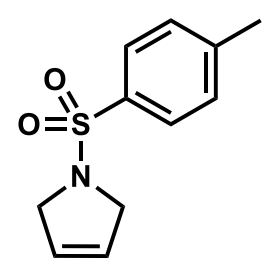

2,5-dihydro-1-[(4-methylphenyl)sulfonyl]-1H-pyrrole. General Procedure 3 produced the title compound as a white solid. ${ }^{1} \mathbf{H}$ NMR $\left(500 \mathrm{MHz}\right.$, Toluene- $\left.d_{8}\right) \delta 7.64(\mathrm{~d}, J=8.3 \mathrm{~Hz}, 2 \mathrm{H})$, $6.79(\mathrm{~d}, J=8.0 \mathrm{~Hz}, 2 \mathrm{H}), 4.98$ (s, 2H), 3.85 (s, 4H), 1.92 (s, 3H). ${ }^{13} \mathrm{C}$ NMR (126 MHz, Toluene$\left.d_{8}\right) \delta 143.12,136.06,130.04,125.85,55.26,30.73,21.44$. HRMS (ESI): $m / z$ calcd for $[\mathrm{M}+\mathrm{H}]^{+}$ $\mathrm{C}_{11} \mathrm{H}_{14} \mathrm{NO}_{2} \mathrm{~S}: 224.0745$ Found: 224.0744.

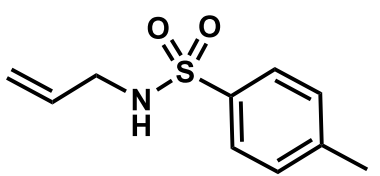

N-allyl-4-methylbenzenesulfonamide. Tosyl chloride $(2.29 \mathrm{~g}, 12 \mathrm{mmol})$ and triethylamine $(1.67 \mathrm{~mL}, 12 \mathrm{mmol})$ were added to a solution of allylamine $(0.90 \mathrm{~mL}, 12$ $\mathrm{mmol})$ in $40 \mathrm{~mL}$ of dichloromethane. The reaction was stirred at room temperature for 5 hours. The reaction was then diluted with diethyl ether and washed water, then brine. The organic layer was dried over $\mathrm{Na}_{2} \mathrm{SO}_{4}$ and concentrated under rotary evaporation. The resulting residue was purified by column chromatography on silica gel (95:5 hexanes: ethyl acetate) to give the title compound (2.04 g, $82 \%)$ as a white solid. All spectra are in agreement with those reported previously. ${ }^{3}{ }^{1} \mathbf{H}$ NMR (500 MHz, Chloroform- $d$ ) $\delta 7.76(\mathrm{~d}, J=8.2 \mathrm{~Hz}, 2 \mathrm{H}), 7.32(\mathrm{~d}, J=8.5 \mathrm{~Hz}, 2 \mathrm{H}), 5.72(\mathrm{ddt}, J=17.3,10.3,5.8 \mathrm{~Hz}, 1 \mathrm{H}), 5.20-$ $5.08(\mathrm{~m}, 2 \mathrm{H}), 4.40(\mathrm{~s}, 1 \mathrm{H}), 3.59(\mathrm{tt}, J=5.9,1.5 \mathrm{~Hz}, 2 \mathrm{H}), 2.43(\mathrm{~s}, 3 \mathrm{H}) .{ }^{13} \mathrm{C}$ NMR $(500 \mathrm{MHz}$, Chloroform- $d) \delta$ 143.68, 137.10, 133.13, 129.88, 127.30, 117.90, 45.95, 21.6 HRMS (ESI): $m / z$ calcd for $\left[\mathrm{M}+\mathrm{H}^{+} \mathrm{C}_{10} \mathrm{H}_{214} \mathrm{NO} \mathrm{O}_{2} \mathrm{~S}\right.$ : 212.0745 Found: 212.0740.

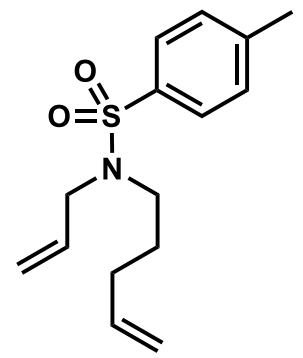

N-allyl-N-(pent-4-enyl)-4-methylbenzenesulfonamide. 5-bromo-1-pentene $(0.24 \mathrm{~mL}, 2.02$ mmol) was added to a solution of $\mathrm{N}$-allyl-4-methylbenzenesulfonamide and $\mathrm{K}_{2} \mathrm{CO}_{3}(836 \mathrm{mg}$, $6.06 \mathrm{mmol}$ ) in $25 \mathrm{~mL}$ of acetonitrile and refluxed for 48 hours. The solution was filtered through a pad of celite before being concentrated under rotary evaporation. The crude residue was subjected to column chromatography on silica gel (85:15 hexanes: ethyl acetate) to give the title compound (190 mg, 34\%) as a clear oil. ${ }^{1} \mathbf{H}$ NMR $\left(500 \mathrm{MHz}\right.$, Toluene- $\left.d_{8}\right) \delta 7.63(\mathrm{~m}$, $2 \mathrm{H}), 6.80$ (d, $J=8.0 \mathrm{~Hz}, 2 \mathrm{H}), 5.66$ (ddt, $J=16.9,10.1,6.6 \mathrm{~Hz}, 1 \mathrm{H}), 5.52$ (ddt, $J=16.6,10.1$, $6.4 \mathrm{~Hz}, 1 \mathrm{H}), 4.99-4.91(\mathrm{~m}, 2 \mathrm{H}), 4.91-4.81(\mathrm{~m}, 2 \mathrm{H}), 3.60(\mathrm{dd}, J=6.4,1.5 \mathrm{~Hz}, 2 \mathrm{H}), 2.98$ $(\mathrm{m}, 2 \mathrm{H}), 1.95(\mathrm{~s}, 3 \mathrm{H}), 1.88(\mathrm{~m}, 2 \mathrm{H}), 1.49(\mathrm{p}, J=7.5 \mathrm{~Hz}, 2 \mathrm{H}) .{ }^{13} \mathrm{C}$ NMR (126 MHz, Toluene- $\left.d_{8}\right) \delta 142.88,138.94$,

\footnotetext{
${ }^{3}$ Che, C.; Li, W.; Lin, S.; Chen, J.; Zheng, J.; Wu, J.; Zheng, Q.; Zhang, G.; Yang, Z.; Jiang, B. Magnetic NanoparticleSupported Hoveyda-Grubbs Catalysts for Ring-Closing Metathesis Reactions. Chem. Commun. 2009, No. 40, 5990-5992. $\underline{\text { https://doi.org/10.1039/B911999J. }}$
} 
138.37, 134.68, 129.98, 127.95, 118.42, 115.52, 51.33, 47.53, 31.46, 28.25, 21.44. HRMS (ESI): $\mathrm{m} / \mathrm{z}$ calcd for $[\mathrm{M}+\mathrm{H}]^{+} \mathrm{C}_{15} \mathrm{H}_{22} \mathrm{NO}_{2} \mathrm{~S}: 280.1371$ Found: 280.1372 .<smiles>Cc1ccc(S(=O)(=O)N2CC=CCCC2)cc1</smiles>

1-tosyl-2,5,6,7-tetrahydro- $1 \mathrm{H}$-azepine. General Procedure 3 produced the title compound as a colorless oil. ${ }^{1} \mathbf{H}$ NMR $\left(500 \mathrm{MHz}\right.$, Toluene- $\left.d_{8}\right) \delta 7.60(\mathrm{~d}, J=8.3 \mathrm{~Hz}, 2 \mathrm{H}), 6.82(\mathrm{~d}, J=7.9 \mathrm{~Hz}$, $2 \mathrm{H}), 5.51-5.36(\mathrm{~m}, 2 \mathrm{H}), 3.60-3.55(\mathrm{~m}, 2 \mathrm{H}), 3.15-3.07(\mathrm{~m}, 2 \mathrm{H}), 1.96(\mathrm{~s}, 3 \mathrm{H}), 1.87-1.77$ $(\mathrm{m}, 2 \mathrm{H}), 1.43-1.33(\mathrm{~m}, 2 \mathrm{H}) .{ }^{13} \mathbf{C}$ NMR $\left(125 \mathrm{MHz}\right.$, Toluene- $\left.d_{8}\right) \delta 142.70,138.24,132.89$, 129.84, 127.99, 127.70, 50.01, 47.02, 27.50, 27.28, 21.46. HRMS (ESI): $\mathrm{m} / \mathrm{z}$ calcd for $[\mathrm{M}+\mathrm{H}]^{+}$ $\mathrm{C}_{13} \mathrm{H}_{18} \mathrm{NO}_{2} \mathrm{~S}: 252.1058$ Found: 252.1064.

4,4-dicarbethoxyl-1-cyclopentene. General Procedure 3 produced the title compound as a colorless oil. ${ }^{1} \mathbf{H}$ NMR $\left(500 \mathrm{MHz}\right.$, Toluene- $\left.d_{8}\right) \delta 5.39(\mathrm{~s}, 2 \mathrm{H}), 3.93(\mathrm{q}, J=7.1 \mathrm{~Hz}$, $4 \mathrm{H}), 3.11(\mathrm{~s}, 4 \mathrm{H}), 0.92(\mathrm{t}, J=7.1 \mathrm{~Hz}, 6 \mathrm{H}) .{ }^{13} \mathbf{C}$ NMR $\left(500 \mathrm{MHz}\right.$, Toluene- $\left.d_{8}\right) \delta$ 171.40, 60.82, 58.80, 40.89, 13.62. HRMS (ESI): $\mathrm{m} / \mathrm{z}$ calcd for $[\mathrm{M}+\mathrm{Na}]^{+} \mathrm{C}_{11} \mathrm{H}_{16} \mathrm{O}_{4} \mathrm{Na}$ :

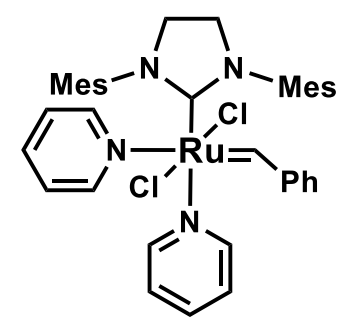

$(\mathrm{SIMes})\left(\mathrm{C}_{5} \mathrm{H}_{5} \mathbf{N}\right)_{2}(\mathrm{Cl})_{2} \mathbf{R u}=\mathrm{CHPh}(\mathrm{GC3})$. Pyridine $(2 \mathrm{~mL}, \mathrm{X} \mathrm{mmol})$ was added to a round bottom flask containing Grubbs' second generation catalyst $(250 \mathrm{mg}, 0.29 \mathrm{mmol})$ and stirred to produce a green color. Pentane was layered onto the solution and left overnight at $-20{ }^{\circ} \mathrm{C}$. The precipitated green solid was filtered and washed with cold pentane before being dried under vacuum to produce the title compound $(204 \mathrm{mg}, 97 \%)$ as a green, crystalline solid. All spectra are in agreement with those reported previously. ${ }^{4}$

\footnotetext{
${ }^{4}$ Sanford, M. S.; Love, J. A.; Grubbs, R. H. A Versatile Precursor for the Synthesis of New Ruthenium Olefin Metathesis Catalysts. Organometallics 2001, 20 (25), 5314-5318. https://doi.org/10.1021/om010599r.
} 
<smiles>[AlH2]</smiles>

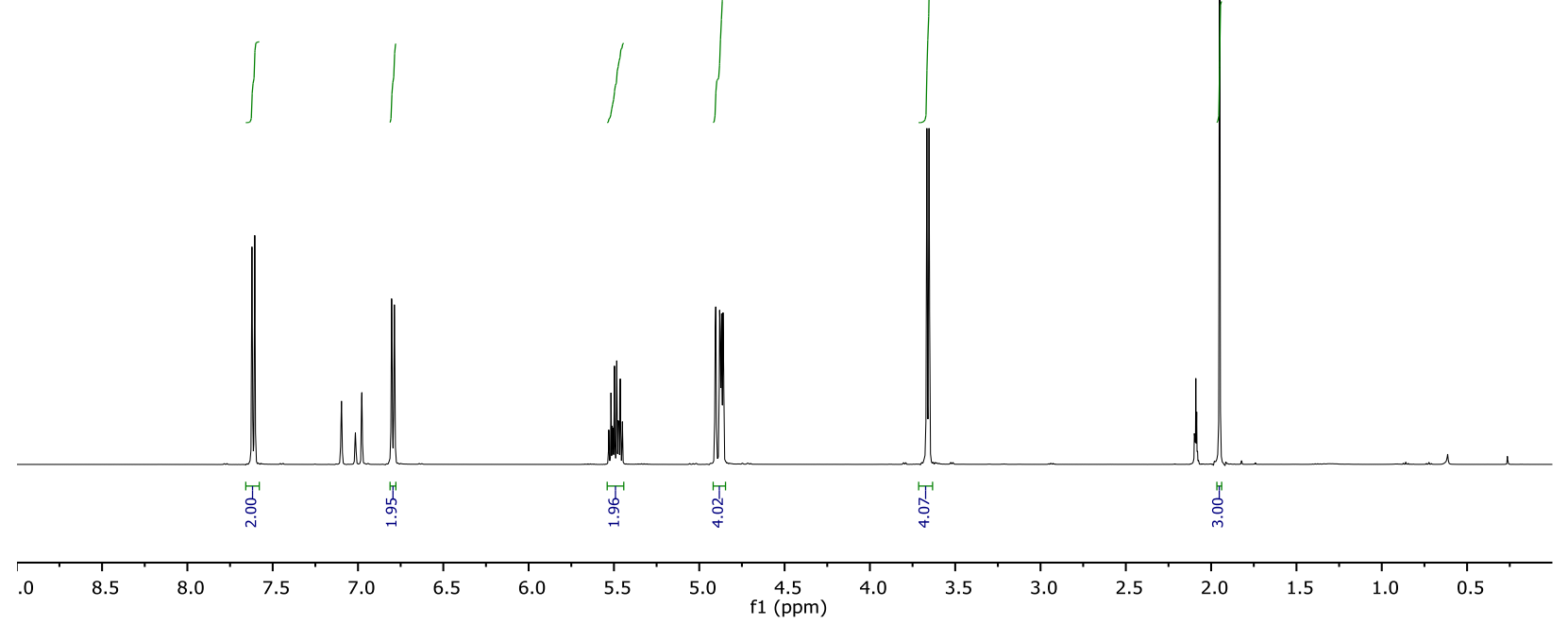<smiles>C=CCN(CC=C)S(=O)(=O)c1ccc(C)cc1</smiles>

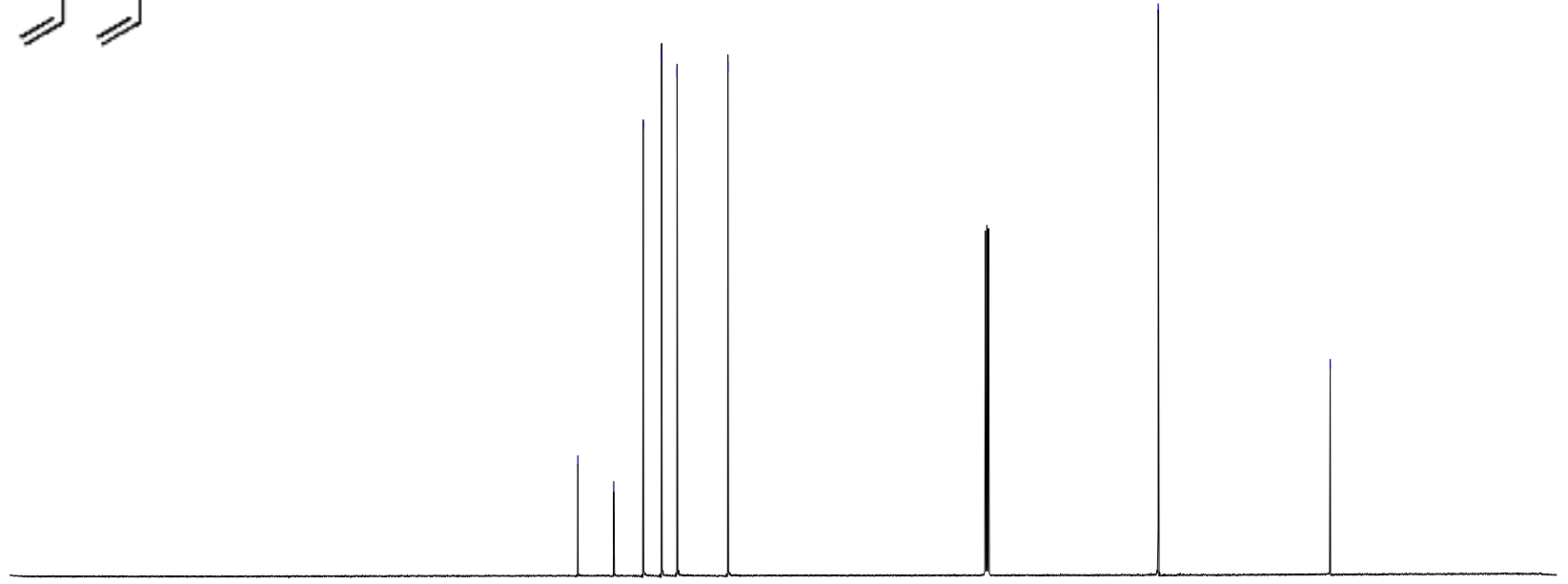

\begin{tabular}{lllllllllllllllllllllllllllllll}
\hline 230 & 220 & 210 & 200 & 190 & 180 & 170 & 160 & 150 & 140 & 130 & 120 & 110 & 100 & 90 & 80 & 70 & 60 & 50 & 40 & 30 & 20 & 10 & 0 & -10
\end{tabular} 

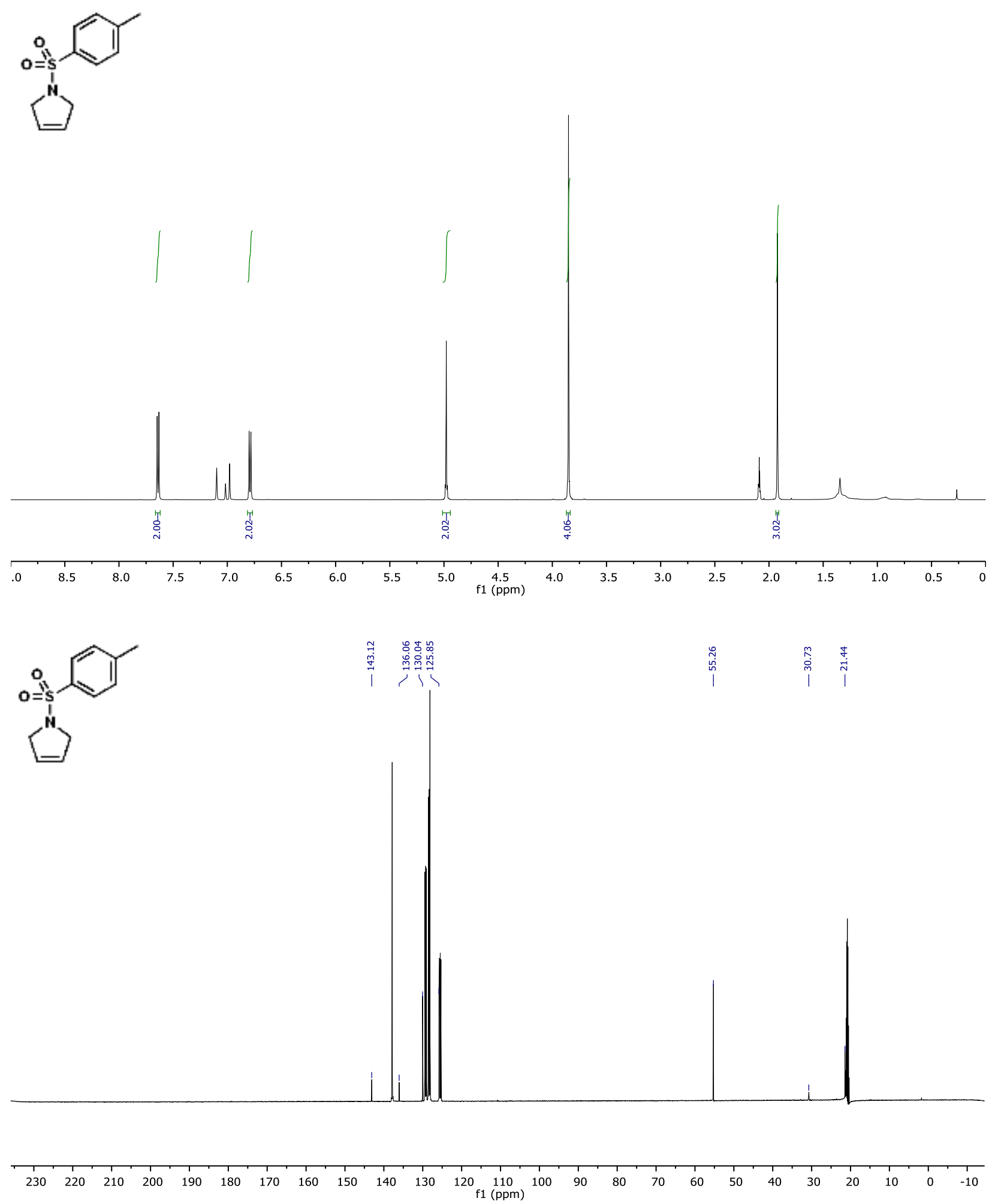

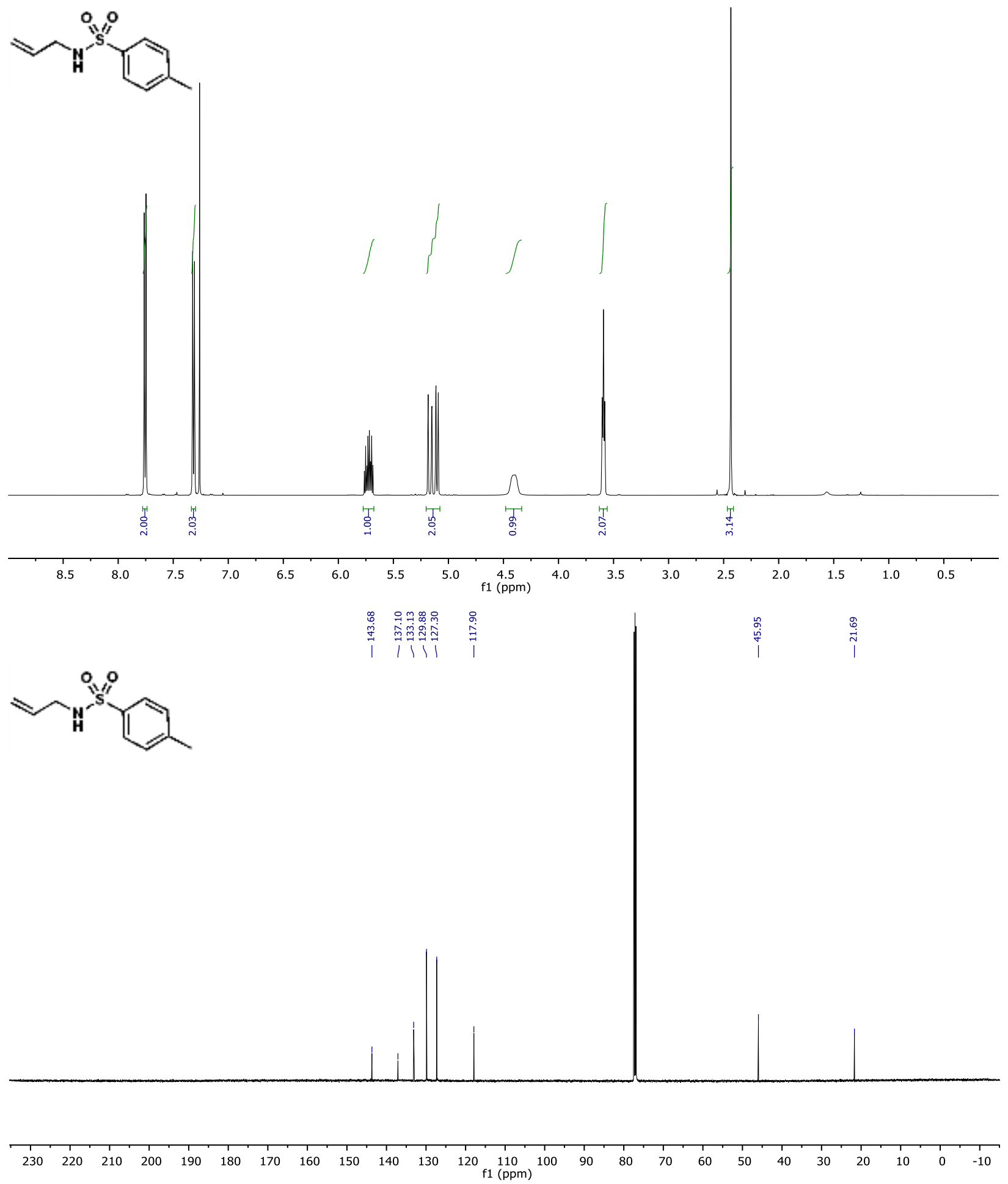

S14 
<smiles>C=CCCN(CC=C)S(=O)(=O)c1ccc(C)cc1</smiles>

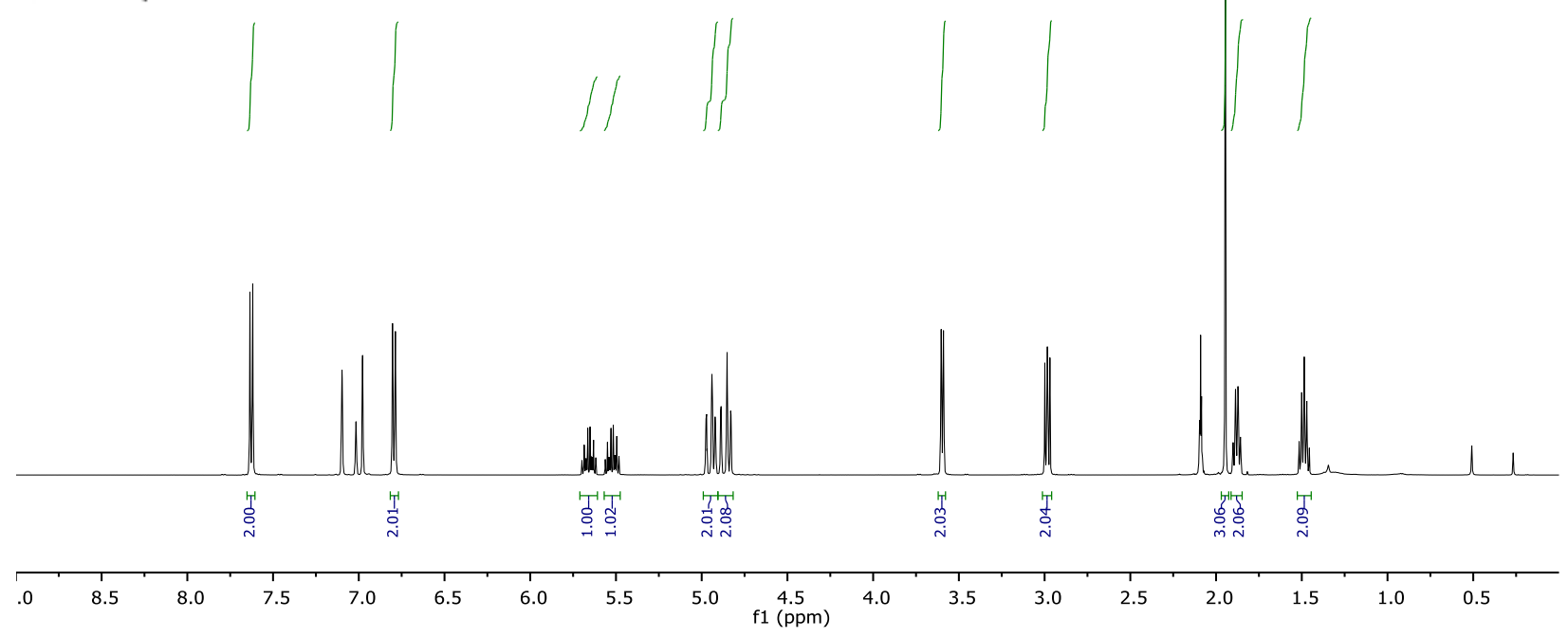<smiles>C=CCCN(CC=C)S(=O)(=O)c1ccc(C)cc1</smiles> 

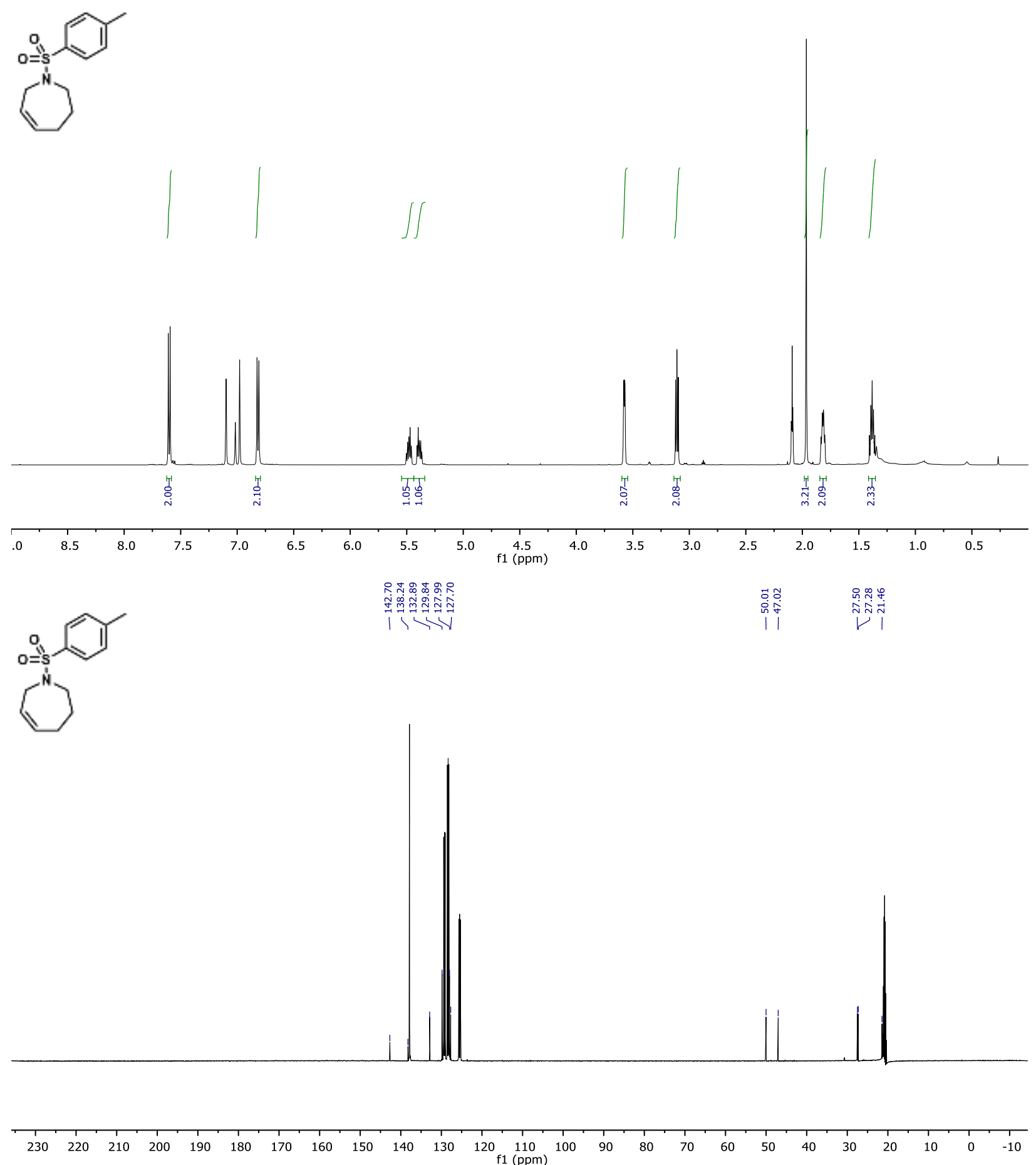

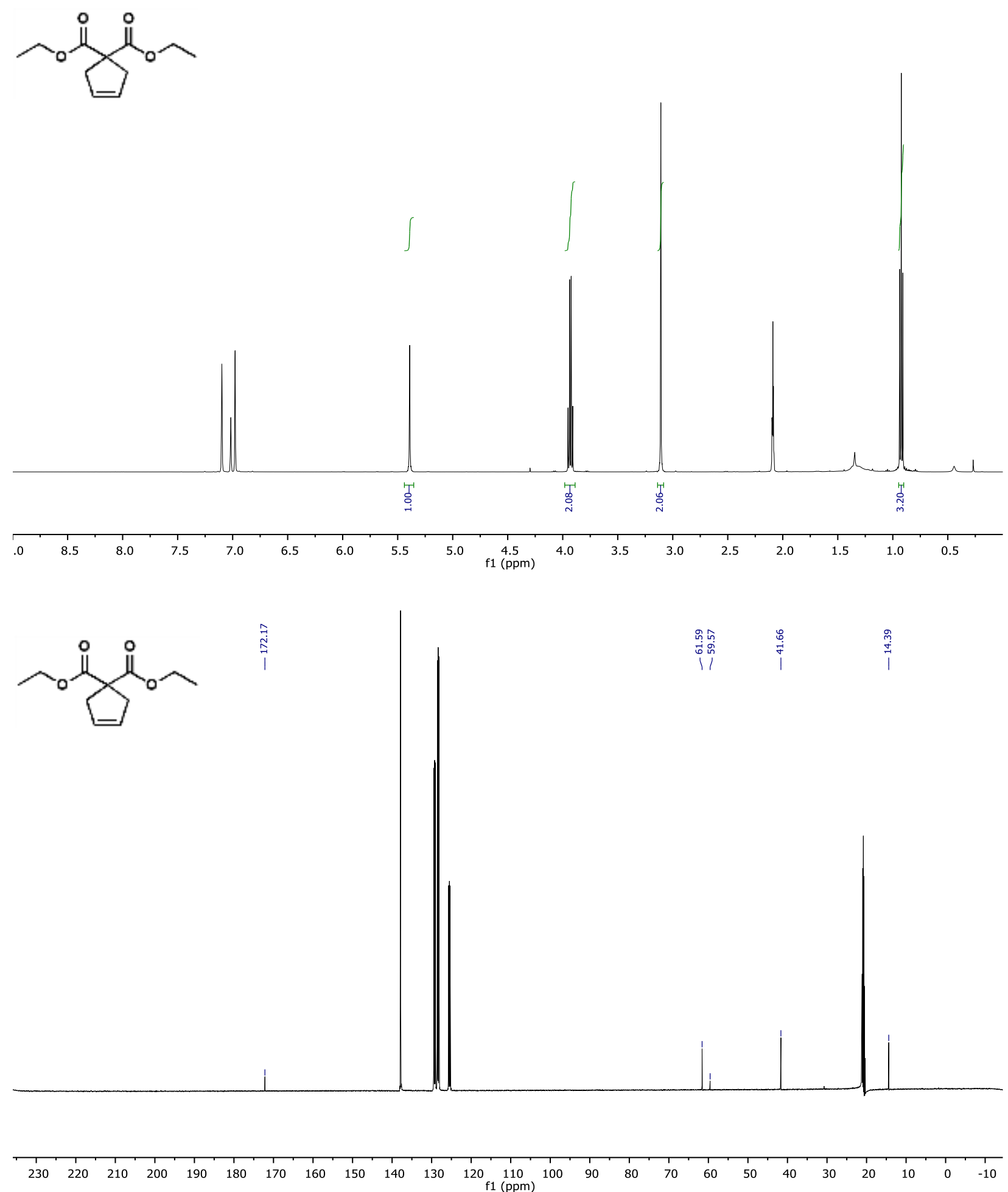